\title{
Donation Behavior in Online Micro Charities: An Investigation of Charitable Crowdfunding Projects
}

\author{
Lili Liu \\ City University of Hong Kong \\ 1lili2@ cityu.edu.hk
}

\author{
Ayoung Suh \\ City University of Hong Kong \\ ayoung.suh@cityu.edu.hk
}

\author{
Christian Wagner \\ City University of Hong Kong \\ c.wagner@cityu.edu.hk
}

\begin{abstract}
Charitable crowdfunding is a burgeoning online micro charity paradigm where fund seekers request micro donations from a large group of potential funders. Despite micro charities have gone digital for more than a decade, our knowledge on individuals' donation behavior in online micro charities (e.g., charitable crowdfunding) remains limited. To fill this gap, this study develops a model that explains individuals' donation behavior in charitable crowdfunding. Our model was tested using data collected from 205 individuals who have read charitable crowdfunding projects. The results reveal that empathy and perceived credibility of charitable crowdfunding jointly determine a funder's intention to donate money. Furthermore, website quality and project content quality positively influence both empathy and perceived credibility. Also noteworthy is that initiator reputation is positively related to perceived credibility while project popularity is positively associated with empathy. The findings contribute to a more nuanced understanding of individuals' donation behavior in online micro charities.
\end{abstract}

\section{Introduction}

Charitable crowdfunding - an emerging online micro charity paradigm - is defined as an open call over the internet for monetary donations to realize specific charity needs $[5 ; 24 ; 30]$. In fact, micro charities have a long history in the world. For example, in 1938, the March of Dimes Foundation was established to improve the health of mothers and babies. It has raised a great deal of money from large audiences, where each contributor provides micro donations [69]. Since internet has risen in popularity over the past decade, online micro charities (e.g., charitable crowdfunding) - a remarkable innovation of charity-become the mainstream charity participation mode [71]. Due to significant reductions in coordination and transaction costs brought about by information technology, it is stated that charitable crowdfunding are more effective in encouraging donation behavior than traditional charities $[19 ; 55]$.

Charitable crowdfunding has received substantial attention from practitioners and scholars [19]. In contrast to traditional charities, charitable crowdfunding have three distinctive characteristics: (1) charitable crowdfunding are initiated by individuals rather than government or government-owned nonprofit organizations [24]; (2) charitable crowdfunding focused on specific and size-limited charity causes [71]; (3) charitable crowdfunding use web-based social network sites (SNS) to facilitate interactions among initiators and donors, and provide real-time update on the process of donation [65]. A number of studies have explored the inducements of contributing to micro charities that there is no explicit reward in return $[4 ; 63]$. In traditional micro charities, funders often cite altruistic reasons such as empathy to explain their willingness to donate [19; 64]. With the migration of micro charities to online platforms, funder motivations may change. Contributions may be affected by technology factors, which lower the effort of giving and make smaller donations worthwhile [55]. Online sites may also affect perceived recipient credibility, which has long been a challenge for online money spending [36]. Yet previous studies have not empirically investigated whether perceived credibility or empathy affect the donation behavior in charitable crowdfunding. Correspondingly, the mechanisms and dynamics of funders' empathy and perception of credibility are not well understood [1].

Upon success, charitable crowdfunding is especially beneficial for the society because it is able to raise a lot of money within a short period, hence provide sufficient and timely support to help seekers, in many cases save their lives $[8 ; 18]$. However, a great number of charitable crowdfunding projects failed to achieve their monetary goals [43]. Many charitable 
crowdfunding are organized under the all-or-nothing policy, where the fundraising goal must be achieved within a period, or else the initiator receives no money. Therefore, it is crucial to understand how to design and implement successful charitable crowdfunding initiatives. More specifically, systematic approaches are required to investigate the determinants of funders' intention to donate money in charitable crowdfunding. Few scholars have examined this phenomenon thoroughly in the information systems (IS) discipline. For instance, existing studies have not distinguished the incentives of funders from that of initiators in charitable crowdfunding $[30 ; 51 ; 55]$. In addition, current investigation on charitable crowdfunding is limited to exploratory studies [57]. Motivated by these research gaps, we develop a model that predicts funders' intention to donate for charitable crowdfunding projects. Drawing on the studies of Lee et al. [48] and Kim et al. [45], we identify empathy and perceived credibility of charitable crowdfunding as main determinants for intention to donate and explore how two environmental cues-technological characteristic and crowdfunding project characteristics - affect funders' empathy and perception of project credibility.

The remainder of this paper is organized as follows. First, we provide a review of relevant literature. We then present the research model and hypotheses development and, in the subsequent section, describe the methodology and data analysis. The paper concludes by outlining the implications for theory and practice.

\section{Literature review}

\subsection{Charitable crowdfunding and intention to donate}

The goal of crowdfunding - either charitable or commercial - is to harness the power of the crowd to turn a project unlikely to be realized by traditional means of funding into a reality [46]. It is predicted that global crowdfunding has raised $\$ 5.1$ billion in 2013 and will reach $\$ 1$ trillion in 2025 [20]. Crowdfunding projects differ significantly in their mode of operation. Four primary types of crowdfunding have been identified based on what funders receive in exchange for their contribution [9], such as equity shares (equitybased), a product or service or other non-monetary rewards (reward-based), or a particular interest rate (lending-based). And finally there is donation-based crowdfunding or charitable crowdfunding, where the funders receive no material reward [56]. These four types of crowdfunding feature very different modes of operation and are usually analyzed separately. In this study we focus on one of these types by particularly analyzing charitable crowdfunding.

The term "charity" commonly refers to "the giving of aid to the needy" [54]. More specifically, donation in charitable crowdfunding refers to the giving of monetary aid to the needy. In general, a charitable crowdfunding project involves three parties: the project initiator, who proposes the idea to be funded; funders whose donations support the project; and platforms, which bring project initiators and funders together to launch the project [55]. Charitable crowdfunding platforms, such as Kiva, Chuffed, and Pledgie, provide opportunities for any initiator to launch a project and request a certain amount of money that needs to be raised in a pre-specified duration [57]. Two largest Social Network Sites (SNSs) in Mainland China (Weibo and WeChat), also serve as charitable crowdfunding platforms that lets users raise money for charitable purposes. For instance, "weigongyi" in Weibo and "qingsongchou" in WeChat are two famous charity fundraising channels. A charitable crowdfunding project launched on SNSs has a fast and far-reaching means of broadcasting information to the large pool of users and building widespread support [46], which maximize the chance of its success [55].

Intention to donate is important in charitable crowdfunding research, yet has not received in-depth investigation. The stimulus-organism-response (S-OR) framework has been widely adopted to interpret user behavior online (e.g., online purchase behavior) [50]. S-O-R model posits that cues perceived in the situated environment (stimuli) trigger one's internal evaluation (organism), which subsequently brings about positive or negative behavior (response) in relation to the stimuli [40]. Drawing on the S-O-R model, this paper examines an aspect of online donation behavior that, to the very best of our knowledge, has not been investigated, namely how environmental cues (stimuli) induce funders' perceived credibility and empathy (organism), which in turn impact their intention to donate (response) in charitable crowdfunding projects.

\subsection{Empathy and Perceived Credibility}

Charitable crowdfunding can be framed as a type of philanthropy [29]. Hence, we expect some of the key factors identified in philanthropy to play a role in the context of charitable crowdfunding. Previous research has identified a number of factors that may encourage or inhibit donation behavior. In particular, researchers have found that funders are stimulated to donate money because of their feelings of empathy toward specific crowdfunding projects $[30 ; 61]$. In this 
context, empathy pertains to the extent to which a funder feels compassion for the particular target (i.e., fund seekers), which represents funders' emotional state [37].

Moreover, IS research has found that online behavior is facilitated by perceptions of the source credibility [15]. In charitable crowdfunding, funders' monetary donations are made with no expectation of material rewards. Therefore, we expect concerns about credibility to be relevant for funders. Those who fund in charitable crowdfunding care about whether their donation will be abused for another purpose. Thus, before donating money, funders will evaluate whether a project is credible. Credibility is defined here as a perceptual variable of crowdfunding projects rather than as an objective measure of such projects, which represents funders' cognitive state [45]. In other words, credibility is a property that is judged by the funders who participate in crowdfunding rather than a property of a crowdfunding project per se [27]. Accordingly, we identify empathy (emotional state) and perceived credibility (cognitive state) as predictors of intention to donate in this study.

\subsection{Environmental Cues}

Environmental cues have been found to influence donation behavior in that individuals may experience the intention to donate money when they are stimulated by certain circumstantial factors while reviewing crowdfunding projects $[6 ; 55]$. Previous research has suggested that technological characteristic and crowdfunding project characteristics are important factors of donation behavior $[5 ; 29 ; 30 ; 55 ; 57]$. In this study, technological characteristic is represented by website quality, of which security [66], navigability [66], visual appeal [66], and convenience of payment [5; 29] are identified as key attributes. Crowdfunding project characteristics refer to the project attributes that relate to the funding decision. These attributes are reputation of initiator [29], popularity of crowdfunding

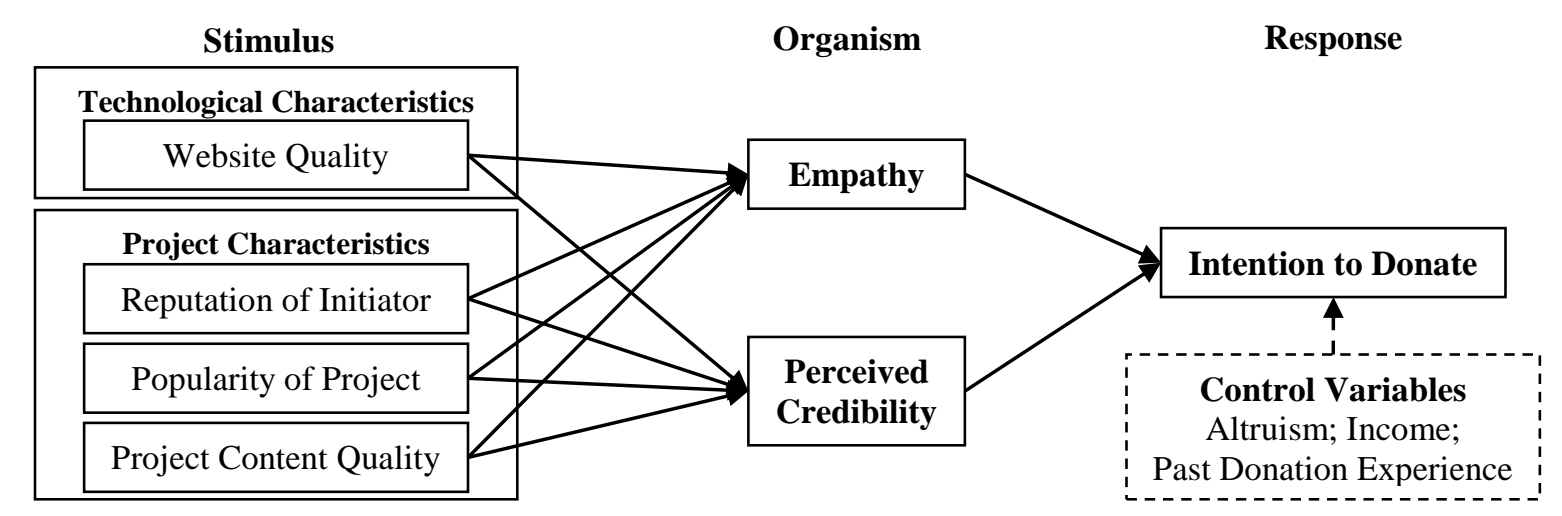

Figure 1. Research model project [51], and crowdfunding project content quality [59].

The environmental cues have been frequently discussed in prior crowdfunding literature $[5 ; 29 ; 30$; 55; 57]. However, there is little knowledge of how these characteristics jointly trigger donation behavior. Collectively, the characteristics stand for the many facets of environmental cues in the context of charitable crowdfunding. Thus, this study extends previous research by investigating whether these cues and their corresponding attributes are major catalysts in increasing empathy and perceived credibility toward a charitable crowdfunding project, which in turn determine the intention to donate money. In doing so, we seek to investigate the relative importance of the two characteristics and their corresponding attributes with respect to their effect on funders' donation behavior.

\section{Research model and hypotheses}

Based on the preceding review, we propose the research model as depicted in Figure 1. Next, we provide detailed support and justification for each of the hypotheses in proposed model.

\subsection{Organism: empathy and perceived credibility}

Empathy is defined as "an affective state that stems from the apprehension of another's emotional state or condition" [25]. Empathy relies on automatically activated state matching that produces shared representations and similar emotions [22]; such state matching is prominent wherever humans attempt to attempt to cultivate more just and compassionate feelings [31]. Research finds that empathy motivates 
prosocial behaviors $[3 ; 25]$, such as donating money to charitable crowdfunding projects [48]. Hence, cultivating empathy is a main determinant for intention to donate. Accordingly, we formulate the following hypothesis:

H1. Funders' empathy for a charitable crowdfunding project positively relates to their intention to donate.

Perceived credibility, defined as judgements made by funders regarding the believability of a crowdfunding project in this study [58], has been extensively studied in the context of online transactions $[11 ; 45]$. Previous research has shown that although most of the messages posted on crowdfunding platforms are credible, sometimes the platform is also used to spread misinformation and false rumors [11]. Hence, while reviewing a charitable crowdfunding project, potential funders often rely on their assessment of the project's credibility when deciding whether to donate money [32]. We thus propose:

H2. Funders' perceived credibility of a charitable crowdfunding project positively relates to their intention to donate.

\subsection{Activating internal reactions: stimulus of environmental cues}

Previous studies have described website quality as a form of technological characteristics [66]. In Wells et al.'s study [66], website quality is identified as a high-order construct consisting of three subdimensions, including security, navigability, and visual appeal. Crowdfunding platforms embed online payment systems which facilitate the transactions between initiators and funders [30]. In the context of crowdfunding, technological characteristic not only refers to the attributes of web technologies, but also the payment convenience which is generated by embedded online payment systems [29]. Hence, we add a fourth sub-dimension, convenience of payment to website quality. When website quality is affirmed, an attitude of credibility/trust toward the information/source on the website can be established. [33]. Further, a well-designed website interface induces more positive emotional and cognitive evaluations of crowdfunding projects. For instance, visual appeal has been found to elicit a sharable emotion between audiences [10]. Thus, a welldesigned, high quality website will increase the funders' empathy as well as perceived credibility of a charitable crowdfunding project. We therefore propose the following hypotheses:
H3a. Website quality positively relates to funders' empathy.

H3b. Website quality positively relates to funders' perceived credibility.

Reputation of initiator is defined as the extent to which a funder believes that an initiator is honest and concerned about the funders [38]. This definition corresponds well with the position of researchers [52] that reputation is a quantity of good impressions derived from the underlying website which is globally visible to all members of the network. Prior research has noted that this construct has a positive and direct effect on building positive attitudes (e.g., trust) toward people or objects [41]. Moreover, a favorable reputation can bring several important benefits to individuals or organizations. For instance, people rely on reputation information when they choose partners to work, where they are more willing to apprehend the feelings of reputable partners and support them [38]. We thus hypothesize:

$\mathrm{H} 4 \mathrm{a}$. Reputation of initiator positively relates to funders' empathy.

H4b. Reputation of initiator positively relates to funders' perceived credibility.

Popularity of a crowdfunding project refers to the number of retweets, comments, and likes related to it on social media platforms [21]. Once being launched, crowdfunding projects have a potential to be spread to other websites (e.g., Twitter, Weibo, WeChat) and viewed by potential funders [34]. Apparently, crowdfunding project with great number of retweets, comments, and likes are popular. Prior research has demonstrated that popularity of project serve as a cue and as it increases, potential funders' perceived credibility on that project also increases [42;68]. Moreover, others users' involvement in a charitable crowdfunding project (e.g., retweet the crowdfunding project information, like the project, and comment on the project) is conducive to generate empathy and positive feelings among future viewers, who are potentially become funders of the project [7]. Therefore, we propose the following hypotheses:

H5a. Popularity of project positively relates to funders' empathy.

H5b. Popularity of project positively relates to funders' perceived credibility.

In this study, project content quality is defined as the degree to which the funder believes that the information provided about a crowdfunding project is of high quality [70]. Because it is often the case that multiple crowdfunding projects are concurrently raising money for similar purpose, funders seek 
information about a crowdfunding project that allows them to distinguish a project with high credibility from a project with low credibility by acquiring more detailed information (e.g., the initiator, aim, anticipated amount of money, available period). Empirical findings have supported the observation that project content quality positively influences user's perception of project credibility [28]. In addition, when a charitable crowdfunding project provide complete, accurate, well-formatted, and timeliness information, funders are more likely to generate emotional resonance (e.g., empathy) to it based on a deeper understanding of the project [47]. Thus, we propose:

H6a. Project content quality positively relates to funders' empathy.

H6b. Project content quality positively relates to funders' perceived credibility.

\section{Methods}

We developed a questionnaire to collect data. The questionnaire consisted of seven sections: website quality, reputation of initiator, popularity of project, project content quality, empathy, perceived credibility, and intention to donate. A 7-point Likert scale ranging from 1 (strongly disagree) to 7 (strongly agree) was used as a measurement scale. Website quality was considered as a formative construct consisting of four sub-dimensions. Measurement items for website quality dimensions were adapted from studies of Wells et al. [67] and Kim et al. [44]. Reputation of initiator measurements were adopted from Jarvenpaa et al.'s measurement instruments [39]. Popularity of project items were adopted from Chang et al.'s model [13]. Project content quality measurement items were adopted form $\mathrm{Xu}$ et al.'s research [70]. Items for perceived credibility were adapted from the work of McCroskey and Teven [53]. Empathy measurement items were adapted from Batson et al.'s study [2]. Finally, items for intention to donate were derived from Dodds et al.'s work [23]. Prior research has shown that funders can differ considerably in their general tendency to be altruistic [64]. Hence, altruism was examined as a control variable of intention to donate. We measured an individual's inherent altruism using four items that adapted from Chen et al.'s study [14]. Moreover, consistent with prior study, funders' income and past donation experience were also considered as control variables of intention to donate [6]. In the present study, the wording of the measurement statements was modified to reflect the charitable crowdfunding context.
As we discussed earlier, in Mainland China, SNSs (e.g., WeChat, Weibo) allow initiators to directly post charitable crowdfunding projects, recruit funders, and solicit the required amount of money based on an agreed-upon deadline. It has been argued that use of SNSs may help initiators reach fundraising targets faster [55]. For instance, in 2014, Weibo (Chinese Twitter) announced that within 20 days, 40,000 users collectively donated $\$ 1.5$ million for Amyotrophic Lateral Sclerosis patients, an amount almost five times greater than the total amount of donations to this charitable fund in 2013. Hence, the questionnaire was distributed to Weibo and WeChat users who are familiar with charitable crowdfunding projects. Respondents were asked to recall the latest charitable crowdfunding project they have read (no matter they have donated money or not) and fill out our questionnaire. A survey agency helped to distribute the questionnaire from May 12 to May 26, 2016. We received 205 valid responses. Demographics of the research sample are displayed in Table 1.

Table 1. Subject demographics

\begin{tabular}{llrr}
\hline Item & Category & Frequency & Ratio \\
\hline Gender & Male & 94 & $45.85 \%$ \\
& Female & 111 & $54.15 \%$ \\
\hline Age & $<=20$ & 9 & $4.39 \%$ \\
& $21-30$ & 128 & $57.56 \%$ \\
& $31-40$ & 55 & $26.83 \%$ \\
& $41-50$ & 20 & $9.76 \%$ \\
\hline Education & Below & 54 & $26.35 \%$ \\
& College & 128 & $62.44 \%$ \\
& Postgraduate & 20 & $9.76 \%$ \\
& Above & 3 & $1.46 \%$ \\
\hline Income & $<=2,000$ & 24 & $11.71 \%$ \\
(CNY) & $2,001-5,000$ & 91 & $44.39 \%$ \\
& $5,001-8,000$ & 56 & $27.32 \%$ \\
& $8,001-$ & 24 & $11.71 \%$ \\
& $>15,000$ & 10 & $4.88 \%$ \\
\hline Past & Never & 48 & $23.41 \%$ \\
Donation & Seldom & 64 & $31.22 \%$ \\
Experience & Sometimes & 81 & $39.51 \%$ \\
& Frequently & 12 & $5.85 \%$ \\
\hline
\end{tabular}

\section{Results}

The data analysis was conducted in two stages. In stage one, the appropriateness of measurement model, including reliability, validity, and common method bias, was examined. In stage two, the structural model and hypotheses were assessed and tested respectively [17]. The data was analyzed using SmartPLS 2.0 [62].

\subsection{Measurement model}

Reliability was assessed by examining Cronbach's alpha, composite reliability (CR), and 
average variance extracted (AVE) [35]. The threshold values used to evaluate these three indices were 0.7 , 0.7 , and 0.5 , respectively [16]. For the reflective constructs, convergent validity was assessed by examining whether the item loadings on the corresponding constructs were large enough. For the formative constructs, the item weights were checked. As shown in Table 2, all item loadings of reflective constructs were significant $(\mathrm{p}<.001)$, and almost all item loadings were above 0.7 , indicating adequate convergent validity [26].

Table 2. Item means and loadings of reflective constructs

\begin{tabular}{|c|c|c|c|c|c|c|}
\hline Constructs & Items & Mean & Loading & $\begin{array}{c}\mathrm{T}- \\
\text { value }\end{array}$ & $\alpha$ & C.R. \\
\hline \multirow{5}{*}{$\begin{array}{l}\text { Reputation } \\
\text { of Initiator }\end{array}$} & REP1 & 5.65 & 0.68 & 15.29 & \multirow[t]{5}{*}{0.85} & \multirow[t]{5}{*}{0.89} \\
\hline & REP2 & 4.39 & 0.71 & 16.51 & & \\
\hline & REP 3 & 4.40 & 0.77 & 16.54 & & \\
\hline & REP 4 & 5.01 & 0.89 & 54.15 & & \\
\hline & REP 5 & 5.08 & 0.88 & 48.78 & & \\
\hline \multirow{3}{*}{$\begin{array}{l}\text { Popularity } \\
\text { of Project }\end{array}$} & POP1 & 5.45 & 0.87 & 34.95 & \multirow[t]{3}{*}{0.88} & \multirow[t]{3}{*}{0.93} \\
\hline & POP2 & 5.49 & 0.93 & 83.74 & & \\
\hline & POP3 & 5.38 & 0.90 & 53.70 & & \\
\hline \multirow{3}{*}{$\begin{array}{l}\text { Project } \\
\text { Content } \\
\text { Quality }\end{array}$} & CON1 & 5.23 & 0.93 & 70.43 & \multirow[t]{3}{*}{0.93} & \multirow[t]{3}{*}{0.95} \\
\hline & CON2 & 5.38 & 0.94 & 107.61 & & \\
\hline & CON3 & 5.18 & 0.93 & 68.55 & & \\
\hline \multirow{6}{*}{ Empathy } & EMP1 & 5.81 & 0.61 & 8.33 & \multirow[t]{6}{*}{0.88} & \multirow[t]{6}{*}{0.91} \\
\hline & EMP2 & 5.89 & 0.72 & 14.04 & & \\
\hline & EMP3 & 5.40 & 0.79 & 22.45 & & \\
\hline & EMP4 & 5.66 & 0.86 & 46.36 & & \\
\hline & EMP5 & 5.40 & 0.85 & 38.58 & & \\
\hline & EMP6 & 5.75 & 0.85 & 32.17 & & \\
\hline \multirow{6}{*}{$\begin{array}{l}\text { Perceived } \\
\text { Credibility }\end{array}$} & CRE1 & 5.32 & 0.91 & 53.76 & \multirow[t]{6}{*}{0.94} & \multirow[t]{6}{*}{0.96} \\
\hline & CRE2 & 5.28 & 0.91 & 67.11 & & \\
\hline & CRE3 & 5.27 & 0.87 & 42.30 & & \\
\hline & CRE4 & 5.28 & 0.91 & 63.90 & & \\
\hline & CRE5 & 5.19 & 0.88 & 32.10 & & \\
\hline & CRE6 & 4.99 & 0.82 & 28.44 & & \\
\hline \multirow{3}{*}{$\begin{array}{l}\text { Intention } \\
\text { to Donate }\end{array}$} & INT1 & 5.16 & 0.94 & 84.60 & \multirow[t]{3}{*}{0.92} & \multirow[t]{3}{*}{0.95} \\
\hline & INT2 & 5.22 & 0.94 & 107.96 & & \\
\hline & INT3 & 5.23 & 0.90 & 36.98 & & \\
\hline
\end{tabular}

Note: $\alpha=$ Cronbach's Alpha; C.R. = Composite Reliability.

Table 3. Item means and loadings of formative constructs

\begin{tabular}{|c|c|c|c|c|c|c|}
\hline Construct & Item & Mean & Weight & $\begin{array}{c}\text { T- } \\
\text { value }\end{array}$ & Loading & $\begin{array}{c}\text { T- } \\
\text { value }\end{array}$ \\
\hline $\begin{array}{l}\text { Website } \\
\text { Quality }\end{array}$ & SEC & 4.40 & 0.28 & 3.25 & 0.67 & 13.89 \\
\cline { 2 - 7 } & NAV & 5.76 & 0.34 & 3.38 & 0.78 & 21.31 \\
\cline { 2 - 7 } & VIS & 5.24 & 0.26 & 2.32 & 0.73 & 20.54 \\
\cline { 2 - 7 } & CONV & 5.50 & 0.44 & 5.32 & 0.82 & 26.07 \\
\hline
\end{tabular}

Note: SEC = Security; NAV = Navigability; VIS = Visual Appeal; CONVE $=$ Convenience of Payment.
For the formative constructs, namely website quality, all the weights of the four items were significant (see Table 3). Loadings for formative items were further examined and results show that the item loadings were significant, implying their acceptable absolute importance [12].

Discriminant validity of the constructs can be verified by confirming the square root of the AVE to be higher than the inter-construct correlations [26]. The result in Table 4 shows that the square roots of the AVE of all the constructs were higher than all the correlations, suggesting good discriminant validity. Subsequently, following Podsakoff and Organ [60], we tested common method bias (CMB) to prevent from artifactual covariance between variables. The results reveal that no single factor emerged from the Harman's one factor analysis and there was no one single factor that accounts for the majority of the covariance in the independent and criterion variables, revealing that $\mathrm{CMB}$ did not pose a major threat to this study [49].

Table 4. Discriminant validity

\begin{tabular}{|c|c|c|c|c|c|c|c|c|}
\hline & AVE & WQ & REP & POP & CON & EMP & CRE & INT \\
\hline WQ & N/A & N/A & & & & & & \\
\hline REP & 0.63 & 0.37 & 0.79 & & & & & \\
\hline POP & 0.81 & 0.49 & 0.49 & 0.90 & & & & \\
\hline CON & 0.87 & 0.50 & 0.59 & 0.59 & 0.93 & & & \\
\hline EMP & 0.62 & 0.64 & 0.44 & 0.50 & 0.55 & 0.79 & & \\
\hline CRE & 0.78 & 0.56 & 0.53 & 0.50 & 0.67 & 0.54 & 0.89 & \\
\hline INT & 0.86 & 0.62 & 0.45 & 0.57 & 0.61 & 0.61 & 0.61 & 0.93 \\
\hline
\end{tabular}

Note:

1. WQ = Website Quality; REP = Reputation of Initiator; $\mathrm{POP}=$ Popularity of Project; $\mathrm{CON}=$ Project Content Quality; EMP = Empathy; $\mathrm{CRE}=$ Credibility; $\mathrm{INT}=$ Intention to Donate, AVE = Average Variance Extracted. 2. The square root of average variance extracted (AVE) is shown on the diagonal of the correlation matrix.

\subsection{Structural model}

The results of the structural model test are summarized in Figure 2. As hypothesized, empathy $(\beta=0.29, p<0.001)$ and perceived credibility $(\beta=0.34$, $\mathrm{p}<0.001$ ) were positively associated with intention to donate. They jointly explained $55.8 \%$ of the variance in intention to donate. $\mathrm{H} 1$ and $\mathrm{H} 2$ were supported. Website quality had significant effects on both empathy $(\beta=0.44, p<0.001)$ and perceived credibility $(\beta=0.27, \quad p<0.001)$. In addition, project content quality also had significant effects on both empathy $(\beta=0.21, p<0.01)$ and perceived credibility $(\beta=0.42$, $\mathrm{p}<0.001)$. Besides, reputation of initiator had 


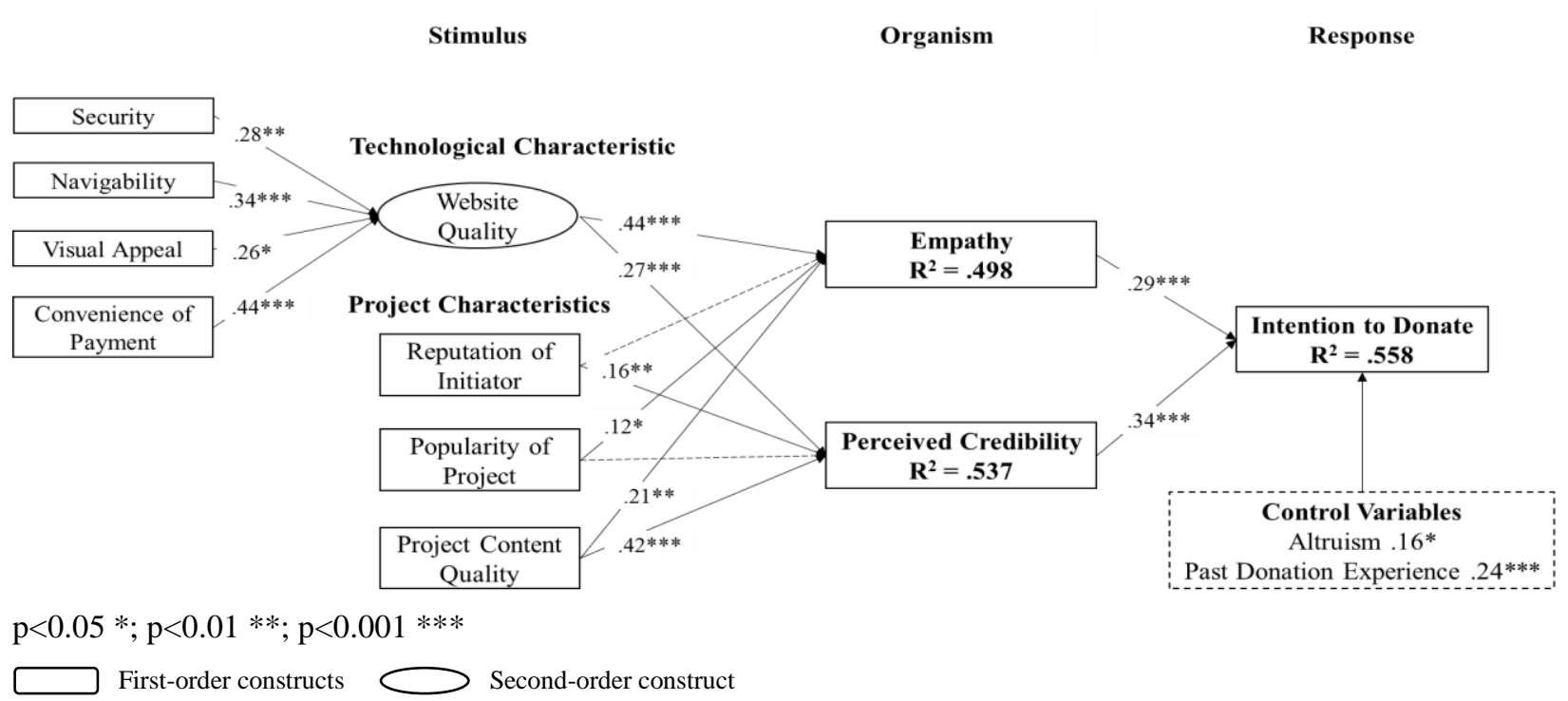

Figure 2. Structural model

significant impact on perceived credibility $(\beta=0.16$, $\mathrm{p}<0.01)$ while popularity of project had significant influence on empathy $(\beta=0.12, \quad \mathrm{p}<0.05)$. The proportions of variances explained were $49.8 \%$ for empathy, and $53.7 \%$ for perceived credibility. H3a, $\mathrm{H} 3 \mathrm{~b}, \mathrm{H} 4 \mathrm{~b}, \mathrm{H} 5 \mathrm{a}, \mathrm{H} 6 \mathrm{a}$ and H6b were supported. We also found that two control variables - altruism $(\beta=0.16$, $p<0.05)$ and past donation experience $(\beta=0.24$, $\mathrm{p}<0.001)$ - had significant influence on intention to donate.

\section{Results}

The main purpose of the study was to explore the determinants of donation behavior in online micro charities (e.g., charitable crowdfunding projects). To do so, we proposed a model that explored the effects of funders' empathy and perceived credibility of a charitable crowdfunding project on their intention to donate, as well as the effects of two environmental cues - technological characteristic (website quality) and project characteristics (reputation of initiator, popularity of project, and project content quality)—on funders' empathy and perceived credibility of a project.

The results provide three key insights. First, there seems to be more evidence that funders' empathy and perceived credibility of a charitable crowdfunding project play powerful roles in determining their intention to donate money. Second, evidence is provided for the positive effects of website quality and project content quality on both empathy and perceived credibility. Third, it is noteworthy that reputation of initiator positively related to perceived credibility while popularity of project positively associated with empathy.

The results associated with the impact of technological characteristic (website quality) on empathy warrant further discussion. Prior research on empathy largely considered it a personal characteristic [22; 37; 48] and overlooked how technology (e.g., website quality) stimulates empathy. Our findings add to the literature on empathy by empirically verifying how technology triggers empathy. More specifically, website quality in terms of security, navigability, visual appeal, and convenience of payment are key factors which predict funders' empathy for charitable crowdfunding projects.

\subsection{Theoretical implications}

In this study, we drew on prior micro charities [6; 48] and crowdfunding [29; 45; 55] research to investigate the determinants of donation behavior in charitable crowdfunding projects. The results of this research make a few key contributions to the existing body of knowledge on online micro charities (e.g., charitable crowdfunding) through IS wisdom.

This study is among the first to empirically examine the effects of emotional state (empathy) and cognitive state (perceived credibility) on intention to donate in the context of charitable crowdfunding. It contributes to the IS literature by demonstrating that both emotional and cognitive states positively affect funders' intention to donate. Second, the study identifies technological characteristic (e.g., website quality) and crowdfunding project characteristics (e.g., 
reputation of initiator, popularity of project, information quality) as two environmental cues, and quantifies their influences on emotional and cognitive states (e.g., empathy and perceived credibility). It expands the literature on human computer interaction by conceptualizing and investigating how technology elicits empathy. Third, our approach also contributes to the literature on developing and measuring website quality in online micro charities, and is thus broadly applicable in IS research. We found strong empirical support for the theorized second-order website quality, modeled as a formative construct constituted by the four facets of security, navigability, visual appeal, and convenience of payment. Fourth, while prior research focuses primarily on exploring why people (including both initiators and funders) participate in charitable crowdfunding, the present research contributes to our knowledge by conducting a granular analysis from the perspective of funders. Fifth, this study also contributes to the S-O-R model by 1 ) incorporating both emotional and cognitive states as organism, and 2) adapting and verifying it in the context of online micro charities.

\subsection{Practical implications}

This study also provides important implications for how to better designing and organizing charitable crowdfunding initiatives. We call for practitioners' attention to technological design features and project features. More specifically, our research indicates that website quality, reputation of initiator, popularity of project and project content quality should be strategically managed to elicit empathy and perceived credibility, which might induce intention to donate money to charitable crowdfunding projects.

Since website quality has four components, namely security, navigability, visual appeal, and convenience of payment, managers can enhance website quality by focusing on these aspects. For example, a simplified transaction system that enables funders to manage their donation to crowdfunding projects with minimal effort (i.e., via a small number of clicks), may lead users to believe that accomplish the donation is more convenience. Enhanced convenience of payment boosts empathy and perceived credibility, and thus helps to generate greater intention to donate money.

\subsection{Limitations}

This study has several limitations. First, our data originated from only two crowdfunding platforms, namely Weibo and WeChat, which are essentially social media platforms with extensions that enable crowdfunding. Accordingly, the generalizability to other online micro charity platforms remains in question. Collecting data from other platforms is thus suggested as future research. Besides, we derived environmental cues (including technological characteristic and project characteristics) based on prior micro charity and crowdfunding studies and treated them exclusively as the predictors of empathy and perceived credibility. Other indicators, such as funders' characteristics (e.g., funders' social tie with project initiators and peers), should be investigated as part of future research.

\section{Acknowledgements}

This research was supported in part by a grant No. CityU 21500714 from the Research Grants Council of the Hong Kong SAR awarded to the second author.

This research was supported in part by a grant No. CityU 11507815 from the Research Grants Council of the Hong Kong SAR awarded to the third author.

\section{References}

[1] G.K. Ahlers, D. Cumming, C. Günther, and D. Schweizer. "Signaling in equity crowdfunding," Entrepreneurship Theory and Practice, 39: (4), 2015, pp. 955980.

[2] C.D. Batson, J. Fultz, and P.A. Schoenrade. "Distress and empathy: Two qualitatively distinct vicarious emotions with different motivational consequences," Journal of Personality, 55: (1), 1987, pp. 19-39.

[3] C.D. Batson, T.R. Klein, L. Highberger, and L.L. Shaw. "Immorality from empathy-induced altruism: When compassion and justice conflict," Journal of Personality and Social Psychology, 68: (6), 1995, pp. 1042-1054.

[4] R. Bekkers, and P. Wiepking. "A literature review of empirical studies of philanthropy: Eight mechanisms that drive charitable giving," Nonprofit and Voluntary Sector Quarterly, 40: (5), 2010, pp. 924-973.

[5] P. Belleflamme, T. Lambert, and A. Schwienbacher. "Crowdfunding: Tapping the right crowd," Journal of Business Venturing, 29: (5), 2014, pp. 585-609.

[6] R. Bennett. "Impulsive donation decisions during online browsing of charity websites," Journal of Consumer Behaviour, 8: (2), 2009, pp. 116-134.

[7] B. Bickart, and R.M. Schindler. "Internet forums as influential sources of consumer information," Journal of interactive marketing, 15: (3), 2001, pp. 31-40.

[8] B. Boeuf, J. Darveau, and R. Legoux. "Financing creativity: Crowdfunding as a new approach for theatre projects," Arts Funding, 16: (3), 2014, pp. 33-48.

[9] G. Burtch, A. Ghose, and S. Wattal. "An empirical examination of peer referrals in online crowdfunding," Proceedings of the 2014 International Conference on Information Systems, Auckland, New Zealand, 2014.

[10] K. Capota, M. van Hout, and T. van der Geest. "Measuring the emotional impact of websites: A study on 
combining a dimensional and discrete emotion approach in measuring visual appeal of university websites," Proceedings of the 2007 Conference on Designing Pleasurable Products and Interfaces, Helsinki, Finland: ACM, 2007, pp. 135-147.

[11] C. Castillo, M. Mendoza, and B. Poblete. "Information credibility on twitter," Proceedings of the 20th International Conference on World Wide Web, Hyderabad, India ACM, 2011, pp. 675-684.

[12] R.T. Cenfetelli, and G. Bassellier. "Interpretation of formative measurement in information systems research," MIS Quarterly, 33: (4), 2009, pp. 689-707.

[13] Y.-T. Chang, H. Yu, and H.-P. Lu. "Persuasive messages, popularity cohesion, and message diffusion in social media marketing," Journal of Business Research, 68: (4), 2015, pp. 777-782.

[14] X.-P. Chen, C. Hui, and D.J. Sego. "The role of organizational citizenship behavior in turnover: Conceptualization and preliminary tests of key hypotheses," Journal of Applied Psychology, 83: (6), 1998, pp. 922-931.

[15] M.Y. Cheung, C. Luo, C.L. Sia, and H. Chen. "Credibility of electronic word-of-mouth: Informational and normative determinants of on-line consumer recommendations," International Journal of Electronic Commerce, 13: (4), 2009, pp. 9-38.

[16] W.W. Chin. "The partial least squares approach to structural equation modeling," Modern Methods for Business Research, 295: (2), 1998, pp. 295-336.

[17] W.W. Chin, B.L. Marcolin, and P.R. Newsted. "A partial least squares latent variable modeling approach for measuring interaction effects: Results from a Monte Carlo simulation study and an electronic-mail emotion/adoption study," Information Systems Research, 14: (2), 2003, pp. 189-217.

[18] K. Choy, and D. Schlagwein. "IT affordances and donor motivations in charitable crowdfunding: The" earthship kapita" case," Proceedings of the 2015 European Conference on Information Systems, Münster, Germany, 2015.

[19] K. Choy, D. Schlagwein, and H. Hasan. "Crowdsourcing for a better world: on the relation between IT affordances and donor motivations in charitable crowdfunding," Information Technology \& People, 29: (1), 2016, pp. 221-247.

[20] L. Crowdsourcing. 2012. "Crowdfunding industry report: market trends, composition and crowdfunding platforms," in: Crowdfund Insider. http://www.crowdfundinsider.com/2014/03/34255-

crowdfunding-fraud-big-threat/.

[21] L. De Vries, S. Gensler, and P.S. Leeflang. "Popularity of brand posts on brand fan pages: An investigation of the effects of social media marketing," Journal of Interactive Marketing, 26: (2), 2012, pp. 83-91.

[22] J. Decety, and P.L. Jackson. "A social-neuroscience perspective on empathy," Current Directions in Psychological Science, 15: (2), 2006, pp. 54-58.

[23] W.B. Dodds, K.B. Monroe, and D. Grewal. "Effects of price, brand, and store information on buyers' product evaluations," Journal of Marketing Research, 28: (August), 1991, pp. 307-319.

[24] L. Du, L. Qian, and Y. Feng. "Influences of altruistic motivation, shared vision, and perceived accessibility on microcharity behavior," Social Behavior and Personality: An International Journal, 42: (10), 2014, pp. 1639-1650.
[25] N. Eisenberg, and P.A. Miller. "The relation of empathy to prosocial and related behaviors," Psychological Bulletin, 101: (1), 1987, pp. 91-119.

[26] C. Fornell, and D.F. Larcker. "Evaluating structural equation models with unobservable variables and measurement error," Journal of Marketing Research, 18: (1), 1981, pp. 39-50.

[27] K.S. Freeman, and J.H. Spyridakis. "An examination of factors that affect the credibility of online health information," Technical Communication, 51: (2), 2004, pp. 239-263.

[28] R. Fung, and M. Lee. "EC-trust (trust in electronic commerce): exploring the antecedent factors," In the Proceedings of Fifth Americas Conference on Information Systems, W.D.H. and and D.L. Nazareth (eds.), New York: ACM, 1999, pp. 517-519.

[29] E.M. Gerber, and J. Hui. "Crowdfunding: Motivations and deterrents for participation," ACM Transactions on Computer-Human Interaction (TOCHI), 20: (6), 2013, pp. 133.

[30] E.M. Gerber, J.S. Hui, and P.-Y. Kuo. "Crowdfunding: Why people are motivated to post and fund projects on crowdfunding platforms," Proceedings of the International Workshop on Design, Influence, and Social Technologies: Techniques, Impacts and Ethics, New York: ACM, 2012.

[31] K.E. Gerdes. "Empathy, sympathy, and pity: 21stcentury definitions and implications for practice and research," Journal of Social Service Research, 37: (3), 2011, pp. 230-241.

[32] M.D. Greenberg, and E.M. Gerber. "Learning to fail: experiencing public failure online through crowdfunding," Proceedings of the SIGCHI Conference on Human Factors in Computing Systems, Toronto: ACM, 2014 pp. 581-590.

[33] D.G. Gregg, and S. Walczak. "The relationship between website quality, trust and price premiums at online auctions," Electronic Commerce Research, 10: (1), 2010, pp. 1-25.

[34] Z. Guo, J. Huang, J. He, X. Hei, and D. Wu. "Unveiling the patterns of video tweeting: A sina weibo-based measurement study," Passive and Active Measurement: Springer, 2013 pp. 166-175.

[35] J.F. Hair, W.C. Black, B.J. Babin, R.E. Anderson, and R.L. Tatham. Multivariate data analysis. Pearson Prentice Hall Upper Saddle River, NJ. 2006

[36] D.L. Hoffman, T.P. Novak, and M. Peralta. "Building consumer trust online," Communications of the ACM, 42: (4), 1999, pp. 80-85.

[37] M.L. Hoffman. Empathy and moral development: Implications for caring and justice. New York: Cambridge University Press. 2001

[38] A. Jøsang, R. Ismail, and C. Boyd. "A survey of trust and reputation systems for online service provision," Decision Support Systems, 43: (2), 2007, pp. 618-644.

[39] S.L. Jarvenpaa, N. Tractinsky, and L. Saarinen. "Consumer trust in an internet store: a cross-cultural validation," Journal of Computer-Mediated Communication, 5: (2), 1999, pp. 1-35.

[40] Z. Jiang, J. Chan, B.C. Tan, and W.S. Chua. "Effects of interactivity on website involvement and purchase intention," Journal of the Association for Information Systems, 11: (1), 2010, pp. 34-59. 
[41] B. Jin, J. Yong Park, and J. Kim. "Cross-cultural examination of the relationships among firm reputation, esatisfaction, e-trust, and e-loyalty," International Marketing Review, 25: (3), 2008, pp. 324-337.

[42] S.-A.A. Jin, and J. Phua. "Following celebrities' tweets about brands: The impact of twitter-based electronic wordof-mouth on consumers' source credibility perception, buying intention, and social identification with celebrities," Journal of Advertising, 43: (2), 2014, pp. 181-195.

[43] Kickstarter. 2013. "Q\&A," in: http://www.kickstarter.com/blog/2011-the-stats.

[44] C. Kim, M. Mirusmonov, and I. Lee. "An empirical examination of factors influencing the intention to use mobile payment," Computers in Human Behavior, 26: (3), 2010, pp. 310-322.

[45] J.G. Kim, H.K. Kong, K. Karahalios, W.-T. Fu, and H. Hong. "The power of collective endorsements: credibility factors in medical crowdfunding campaigns," Proceedings of Computer Human Interaction, San Jose, CA, USA: ACM, 2016.

[46] T. Lambert, and A. Schwienbacher. 2010. "An empirical analysis of crowdfunding," in: Social Science Research Network, http://ssrn.com/abstract=1578175. University de Louvain France.

[47] J. Lee, D.-H. Park, and I. Han. "The effect of negative online consumer reviews on product attitude: An information processing view," Electronic Commerce Research and Applications, 7: (3), 2008, pp. 341-352.

[48] S. Lee, K.P. Winterich, and W.T. Ross. "I'm moral, but I won't help you: The distinct roles of empathy and justice in donations," Journal of Consumer Research, 41: (3), 2014, pp. 678-696.

[49] H. Liang, N. Saraf, Q. Hu, and Y. Xue. "Assimilation of enterprise systems: the effect of institutional pressures and the mediating role of top management," MIS Quarterly, 31:(1), 2007, pp. 59-87.

[50] Y. Liu, H. Li, and F. Hu. "Website attributes in urging online impulse purchase: An empirical investigation on consumer perceptions," Decision Support Systems, 55: (3), 2013, pp. 829-837.

[51] C.-T. Lu, S. Xie, X. Kong, and P.S. Yu. "Inferring the impacts of social media on crowdfunding," Proceedings of the 7th ACM international conference on Web search and data mining, New York: ACM, 2014, pp. 573-582.

[52] P. Marsden, and N. Lin. Social structure and networks analysis. Beverley Hills: CA: SAGE. 1982

[53] J.C. McCroskey, and J.J. Teven. "Goodwill: A reexamination of the construct and its measurement," Communications Monographs, 66: (1), 1999, pp. 90-103.

[54] Merriam-Webster. 2015. "Charity." available at: www.merriam-webster.com/dictionary/charity.

[55] A. Moisseyev, "Effect of social media on crowdfunding project results," in: College of Business Administration. University of Nebraska. 2013.

[56] E. Mollick. "The dynamics of crowdfunding: An exploratory study," Journal of Business Venturing, 29: (1), 2014, pp. 1-16.

[57] E. Mollick, "The dynamics of crowdfunding: Determinants of success and failure," in: Social Science Research Network. Rochester, New York. 2012.
[58] D.J. O'keefe. Persuasion: Theory and research. Newbury Park: CA: Sage. 2015

[59] C.-H. Park, and Y.-G. Kim. "Identifying key factors affecting consumer purchase behavior in an online shopping context," International Journal of Retail \& Distribution Management, 31: (1), 2003, pp. 16-29.

[60] P.M. Podsakoff, and D.W. Organ. "Self-reports in organizational research: Problems and prospects," Journal of Management, 12: (4), 1986, pp. 531-544.

[61] S.I. Rick, C.E. Cryder, and G. Loewenstein. "Tightwads and spendthrifts," Journal of Consumer Research, 34: (6), 2008, pp. 767-782.

[62] C.M. Ringle, S. Wende, and A. Will, "SmartPLS 2.0 (beta)." Hamburg. 2005.

[63] A. Sargeant, and E. Jay. Fundraising management: analysis, planning and practice. London: Routledge. 2014.

[64] W.R. Steele, G.B. Schreiber, A. Guiltinan, C. Nass, S.A. Glynn, D.J. Wright, D. Kessler, K.S. Schlumpf, Y. Tu, and J.W. Smith. "The role of altruistic behavior, empathetic concern, and social responsibility motivation in blood donation behavior," Transfusion, 48: (1), 2008, pp. 43-54.

[65] R.D. Waters, E. Burnett, A. Lamm, and J. Lucas. "Engaging stakeholders through social networking: How nonprofit organizations are using Facebook," Public Relations Review, 35: (2), 2009, pp. 102-106.

[66] J.D. Wells, V. Parboteeah, and J.S. Valacich. "Online impulse buying: Understanding the interplay between consumer impulsiveness and website quality" Journal of the Association for Information Systems, 12: (1), 2011, p. 32-56. [67] J.D. Wells, J.S. Valacich, and T.J. Hess. "What signals are you sending? How website quality influences perceptions of product quality and purchase intentions," MIS Quarterly, 35: (2), 2011, pp. 373-396.

[68] D. Westerman, P.R. Spence, and B. Van Der Heide. "A social network as information: The effect of system generated reports of connectedness on credibility on Twitter," Computers in Human Behavior, 28: (1), 2012, pp. 199-206.

[69] A. Whitman. "Basil O'Connor, Polio Crusader, Dies," The New York Times: 2015.

[70] J.D. Xu, I. Benbasat, and R.T. Cenfetelli. "Integrating service quality with system and information quality: an empirical test in the e- service context," MIS Quarterly, 37: (3), 2013, pp. 777-794.

[71] T. Yang. Annual report on China's philanthropy development. Social Sciences Academic Press: Beijing. 2013. 